\title{
A GLOBALIZAÇÃO E O ACESSO EQUITATIVO DO USO DE RECURSOS NATURAIS NA CONTEMPORANEIDADE: UM DIAGNÓSTICO SOB O VIÉS DO PRINCÍPIO DA EQUIDADE INTERGERACIONAL \\ GLOBALIZATION AND EQUITABLE USE OF NATURAL RESOURCES IN THE CONTEMPORARY WORLD: A DIAGNOSIS UNDER THE BIAS OF THE PRINCIPLE OF INTERGENERATIONAL EQUITY
}

\author{
${ }^{1}$ Luís Marcelo Mendes \\ ${ }^{2}$ Jerônimo Siqueira Tybusch
}

\section{RESUMO}

O artigo realizar um diagnóstico sobre como a globalização desencadeia a mercantilização /depredação dos recursos naturais em escala local/global para atender os interesses do mercado e da atuação do princípio da equidade intergeracional para tentar refrear esse fenômeno. A pesquisa vale-se do método dedutivo, bem como se utiliza de aportes dialéticos no intuito de realizar uma análise mais acurada sobre o fenômeno. Num primeiro, momento debruçar-se-á sob como a globalização altera do padrão de consumo dos indivíduos em nível local/global. Por fim, delinear-se-á a atuação do princípio da equidade intergeracional junto ao ordenamento jurídico para tentar coibir a degradação ecológica.

Palavras-chave: Princípio da equidade intergeracional, Recursos naturais, Globalização

\begin{abstract}
Article conduct an assessment of globalization has unleashed the commodification /depredation of natural resources in local/global scale to meet the interests of the market and the performance of the principle of intergenerational equity to try to curb this phenomenon. The research makes use of the deductive method, and uses dialectical contributions in order to implement a more accurate analysis of the phenomenon. At first, time will address under as globalization changes in consumption patterns of individuals in local/global level. Finally, it will take shape-the role of the principle of intergenerational equity by the legal system to try to curb ecological degradation.
\end{abstract}

Keywords: Principle of intergenerational equity, Natural resources, Globalization

\section{INTRODUÇÃO}

\footnotetext{
1 Mestre em Direito pela Universidade Federal de Santa Maria. Universidade Federal de Santa Maria - UFSM, Rio Grande do Sul. Brasil - E-mail: mendesczo@gmail.com

2 Doutor em Ciências Humanas pela Universidade Federal de Santa Catarina. Professor de Direito da Universidade Federal de Santa Maria. Universidade Federal de Santa Maria - UFSM, Rio Grande do Sul. Brasil

E-mail: jeronimotybusch@ufsm.br
} 
O artigo visa demonstrar como o fenômeno da globalização tem atuado no processo de mercantilização/depredação dos recursos naturais por meio de um breve diagnóstico acerca das relações entre indivíduos e o consumo na contemporaneidade, bem como será pautada nesse cenário a atuação do princípio da equidade intergeracional como marco regulador para conter o avanço da degradação do natural por meio da contaminação da legislação internacional/interna, em especial, das normas que regulam o acesso equitativo aos recursos naturais para as gerações presentes e futuras.

Para atingir tal intento, no que tange ao aspecto metodológico usa aporte do método dedutivo no intuito de realizar uma abordagem de maior amplitude sobre o uso/acesso indiscriminado dos recursos naturais, pontuando questões factuais a partir do aporte teórico e bibliográfico atualizado. A pesquisa também faz uso de aportes dialético com vistas a confortar as questões suscitadas a fim de apontar possíveis caminhos para a solução da problemática.

Num primeiro momento, procurar-se-á demonstrar como a globalização será responsável pela instauração de uma sociedade global de rede vinculada ao padrão de consumo. Nesse contexto, social o indivíduo é destituído do seu papel de cidadão para assumir o de consumidor, onde o indivíduo em situação de vulnerabilidade econômica será considerado invisível socialmente, uma vez, que não segue o padrão de consumo imposto pela lógica economicista. Sob essa nova conjectura, estabelecer-se-á o fenômeno da mercantilização/depredação do natural, com vista a assegurar a produção de "novos" bens/produtos para garantir a manutenção do consumo segundo os padrões axiológicos acurados pelo próprio mercado.

Após, buscar-se-á determinar como o preceito da equidade intergeracional poderá atuar como mecanismo regulador do acesso equitativo aos recursos naturais para as gerações presentes sem comprometê-los para as gerações futuras. O princípio da equidade intergeracional visa nortear às legislações internacionais, e nacionais na criação de mecanismos jurídicos para tutelar/proteger o acesso equitativo dos recursos naturais para as gerações presentes e futuras. Frente essa conjectura, se construirá uma nova ética, por meio de um novo imperativo categórico, para pré-determinar um agir coletivo voltado a compor as categorias que irão compor o princípio da equidade intergeracional, com base, na solidariedade e comprometimento entre as gerações, para assim, garantir a manutenção do acesso/uso equitativo dos recursos naturais no âmbito local/global. 


\section{O processo de mercantilização/depredação dos recursos naturais sob a égide da globalização: um breve diagnóstico sobre as relações entre indivíduos e consumo}

O século XX foi marcado por um intenso processo de transformação social, imposto pela era da globalização, com reflexos no modo de vida em escala global. Diante desse cenário emerge a Sociedade Global de Rede $^{1}$ através de um aumento exponencial na área do conhecimento humano e o consequente aprimoramento dos bens/serviços decorrentes do desenvolvimento industrial. Sob esta nova conjectura social afloram transformações de todas as espécies que impactam sobre os diversos aspectos da vida humana e nos impelem a uma nova ordem mundial ${ }^{2}$, a era da globalização na qual o indivíduo não consegue compreender em sua plenitude, e paradoxalmente não deixará de sentir os seus efeitos. (GIDDENS, 2007)

A globalização pode ser dividia em três "ondas" distintas. A "primeira onda" compreende no inicio da Revolução Industrial em 1870 e se estende até 1914, esse período tem por característica marcante os avanços na área tecnológica, em especial, no que se refere ao aprimoramento do sistema de transportes através da utilização de ferrovias e barcos a vapor para o escoamento das matérias primas/produtos e pela consequente mudança no setor energético. Esse processo irá sofrer um refreamento em virtude das duas grandes guerras. (TOSTES, 2004)

\footnotetext{
1 Frente essa concepção a Sociedade Global de Rede na concepção de Castells (1999, p. 43) penetra "[...] em todas as esferas da atividade humana, a revolução da tecnologia da informação será o meu ponto de inicial para analisar a complexidade da nova economia, sociedade e cultura em formação. Essa opção metodológica não sugere que novas formas e processos sociais surgem em consequência de transformação tecnológica. É claro que a tecnologia não determina a sociedade. Nem a sociedade escreve o curso da transformação tecnológica, uma vez, que muitos fatores, inclusive a criatividade e iniciativa empreendedora, intervêm no processo de descoberta científica, inovação tecnológica e ampliações sociais, de forma que o resultado final depende de um complexo padrão interativo. Na verdade, o dilema do determinismo tecnológico é, provavelmente, um problema infundado, dado que a tecnologia é a sociedade, e a sociedade não pode ser entendida ou representada sem suas ferramentas tecnológicas."

2

processo de globalização passa a fustigar/modificar a ordem mundial, para Bauman (1999, p. 07) “a

'globalização' está na ordem do dia; uma palavra da moda que se transforma rapidamente em um lema, uma encantação mágica, uma senha capaz de abrir as portas de todos os mistérios presentes e futuros. Para alguns,

'globalização' é o que devemos fazer se quisermos ser felizes; para outros, é a causa da nossa infelicidade. Para todos, porém, 'globalização' é o destino irremediável do mundo, um processo irreversível; é também um processo que nos afeta a todos na mesma medida e da mesma maneira. Estamos todos sendo 'globalizados' - e isso significa basicamente o mesmo para todos.”
} 
De tal modo, a "segunda onda" tem inicio no final da Segunda Grande Guerra, em 1945, e se estenderia até 1980 nesse lapso temporal ocorre à gestação de um novo modelo econômico global, com foco, no comércio voltado para o investimento em nichos de mercados por intermédio do incremento da produção industrial. O processo de "revolução tecnológica da microinformática", iniciado em 1980, impactará no aprimoramento dos sistemas de transportes e comunicação em escala global auxiliando no desenvolvimento industrial. (TOSTES, 2004)

Já, a "terceira onda" da globalização terá seu início em 1980 e perdurara até a contemporaneidade, a mesma terá por características marcantes a discussão sobre o papel das empresas transnacionais privadas como atores responsáveis por mudanças substanciais no cenário internacional, auxiliando na consequente alteração do padrão econômico mundial e a liquefação do Estado frente a essas transformações (TOSTES, 2004) por meio da hegemonia da política neoliberal, capitaneada pelo governo inglês, e seguida, posteriormente, pelos países hegemônicos vinculados ao modelo econômico capitalista, nesse arquétipo "a globalização é política, tecnológica e cultura, tanto quanto econômica.” (GIDDENS, 2007, p. 21)

Com a derrocada do comunismo soviético, era necessário expandir as benesses do sistema capitalista para todas as nações. Assim, emerge a necessidade dos países se adaptarem à nova ordem econômica mundial, principalmente, os países periféricos, numa perspectiva Norte/Sul. (BEDIN, 2002). A supremacia do regime capitalista se consolidará com ruína do comunismo soviético ${ }^{3}$, esse colapso impacta no modo de vida dos indivíduos em escala global.

A política econômica globalizada mudaria a face das relações sócio-econômicas e culturais das nações. Diante do auspício da globalização ocorre uma mudança na estrutura social em nível mundial, em especial, através da criação de processos econômicos globais que auxiliaram a expandir os "benefícios" gerados pelo capitalismo as nações, no entanto, o fenômeno da "a globalização não está se desenvolvendo de uma maneira equitativa, e está longe de ser inteiramente benéfica em suas conseqüências." (GIDDENS, 2007, p. 25)

\footnotetext{
3 Diante dessa perspectiva, denota-se que "o colapso do comunismo soviético deu maior peso a esses desenvolvimentos, uma vez que nenhum grupo expressivo de países permanece fora deles. Este colapso não foi apenas algo que simplesmente aconteceu. A globalização explica tanto por que quanto como o comunismo soviético acabou. A ex-União Soviética e os países da Europa oriental tinham taxas de crescimento comparáveis às dos países ocidentais até por volta do início da década de 1970. Dessa altura em diante, passaram a ficar rapidamente para trás. O comunismo soviético, com sua ênfase na empresa dirigida pelo Estado e na indústria pesada não podia competir na economia eletrônica global. De maneira semelhante, o controle ideológico e cultural em que a autoridade política comunista se baseava não podia sobreviver na mídia global." (GIDDENS, 2007, p. 24)
} 
A conjectura da globalização sob o viés do sistema financeiro global esta atrelada num tripé econômico neoliberal para regular/manter a lógica do mercado financeiro. Diante desse cenário se torna crível determinar que esse tripé econômico seja constituído pela intervenção mínima da regulação econômica por parte dos Estados; pela criação de "novos direitos" vinculados ao direito de propriedade intelectual sob a ótica internacional; e a subordinação dos Estados às agências multilaterais reguladores vinculadas ao sistema financeiro/comercial internacional. (SANTOS, 2011)

A globalização ocasiona uma metamorfose em nível local/global com intensidade desigual devido à posição hegemônica dos países dentro sistema econômico mundial, tal postura gera conflito na construção/condução das políticas econômicas das nações. Os Estados não conseguem fazer frente à nova ordem econômica mundial. É perceptível que o discurso dos países hegemônicos impõe a lógica do mercado econômico vinculada ao capital junto aos países periféricos numa perspectiva Norte/Sul, haja vista, que a soberania estatal se liquefaz sob a égide da economia onde, "a capacidade instrumental do Estado-Nação está comprometida de forma decisiva pela globalização das principais atividades econômicas, pela globalização da mídia e da comunicação eletrônica e pela globalização do crime.” (CASTELSS, 1999, p. 288)

Os efeitos globalizantes geram inúmeros impactos no âmbito das relações sociais e políticas ao transformar o sistema de classes, por meio da criação de uma classe capitalista transnacional onde as empresas multinacionais assumem o papel de atores centrais na condução das políticas econômicas globais, essa estruturação econômica contribui para aumentar o problema da desigualdade social, de viés econômico, em escala global. Perante essa conjectura sociopolítica, se vislumbra o enfraquecimento da soberania dos Estados que agora são relegados há segundo plano nessa nova ordem (econômica) mundial. 
Diante do aumentou da desigualdade social ocasionado pela má distribuição de renda ${ }^{4}$, em nível mundial, se desencadeia uma crescente precarização nas condições de vida dos indivíduos nos países periféricos, ao seguir essa lógica perversa, o Estado, sob o prisma da política neoliberal, acaba por sonegar as condições estruturais no sentido de resguardar os direitos humanos e/ou fundamentais, essa situação acaba por afetar as questões sociais/ecológicas, tanto em nível local, como global. Assim, para tentar superar esse paradigma "deve existir, portanto, uma constante atitude dialógico/dialética permanente entre o local, regional e global.” (TYBUSCH, 2011, p. 37)

A economia globalizada sob a égide do neoliberalismo deflagra a imaterialização de direitos humanos e/ou fundamentais dos sujeitos devido ao enfraquecimento do poder/soberania dos Estados frete ao poder econômico dessa nova ordem mundial global/invisível. Frente à imaterialização desses direitos se pode determinar que "a economia de atuação global enterra os fundamentos do Estado e da economia nacional. E assim entra em curso uma subpolitização de dimensões impensadas e conseqüências imprevisíveis.” (BECK, 2011, p. 15)

\footnotetext{
4 Diante da má distribuição de renda é possível vislumbrar que "hoje a iniquidade da distribuição da riqueza mundial se agravou nas duas últimas décadas: 54 dos 84 países menos desenvolvidos viram o seu PNB per capta decrescer nos anos 80; em 14 deles a diminuição rondou os 35\%; segundo as estimativas nas Nações Unidas, cerca de 1 bilhão e meio de pessoas (1/4 da população mundial) vivem na pobreza absoluta, ou seja, com um rendimento inferior a um dólar por dois bilhões vivem apenas com o dobro desse rendimento. Segundo o Relatório do Desenvolvimento do Banco Mundial de 1995, o conjunto de países pobres, onde vive 85,2\% da população mundial, detém apenas 21,5\% do rendimento mundial, enquanto o conjunto dos países ricos, com

$14,8 \%$ da população mundial, detém $78,5 \%$ do rendimento mundial. Uma família africana média consome hoje

$20 \%$ menos do que consumia há 25 anos. O aumento das desigualdades tem sido tão acelerado e tão grande que é adequado ver que as últimas décadas como uma revolta das elites contra a redistribuição da riqueza com a qual se põe fim ao período de certa democratização da riqueza iniciado no final da Segunda Guerra Mundial." (SANTOS, 2011, p. 34)
} 
Diante desse cenário, as relações entre homem/natureza/consumo se transformaram em virtude das interações sociais/ecológicas impostas pela conjectura da nova ordem social globalizada. A ação da globalização nas suas várias formas, a concepção de novas tecnologias, a volatilidade da economia de mercado tem tornado tudo descartável, substituível. A constituição desse novo modo de vida acaba por ocasionar uma segregação velada entre os indivíduos, pois "cria um mundo de vencedores e perdedores, um pequeno número na via expressa para a prosperidade, a maioria condenada a uma vida de miséria e desesperança." (GIDDENS, 2007, p. 25)

A globalização liquefaz os laços sociais/ecológicos, esse modelo social impõe ao ser humano um novo modo de vida baseado no consumo, onde o indivíduo é induzido a um "estado de carência perpétua", assim o indivíduo deve consumir para poder legitimar a sua existência frete aos outros indivíduos, a sociedade e o Estado para atender a lógica do capital. Ao fazer uma análise mais acurada se percebe "a maneira como a sociedade atual molda seus membros é ditada primeiro e acima de tudo pelo dever de desempenhar o papel de consumidor." (BAUMANN, 1999, p. 88)

O cidadão-consumidor na perspectiva de Canclini (2006) possui a tendência de pensar sob o prisma transnacional, pois nesse cenário a práxis do consumo edificam e acabam por determinar o status do cidadão-consumidor. Não raro, a práxis do consumo passa a simbolizar a participação/inserção/interação desses sujeitos na comunidade local/global, influenciando o processo de construção de uma racionalidade voltada à constituição de uma sociedade de rede comprometida com o consumismo.

O sujeito moderno, sob a categoria de cidadão-consumidor só existe na medida em que consome, onde "as sociedade se reorganizam para fazer-nos consumidores do século XXI, mas como cidadão, querem levar-nos de volta para o século XVIII." (CANCLINI, 2006, p. 52). Deste modo, a lógica do mercado global tende a criar indivíduos mais preocupados com o acesso a bens de consumo em detrimento da busca pela concretização de direitos/garantias que visem proteger/tutelar uma vida digna, por meio da materialização dos direitos humanos e/ou fundamentais.

O consumismo moderno assume contornos de esquizofrenia ${ }^{5}$ e gera um estado de êxtase entre os indivíduos, pois a individualidade agora passa a ser medida pela exclusividade das marcas dos bens de consumo/produtos utilizados pelos indivíduos. O consumo exacerbado tende a seguir a lógica do mercado, já que são necessários consumidores insaciáveis pela aquisição de novos bens/produtos de consumo. Deste modo, o mercado incita os 
consumidores com "novidades" constantemente, assim, os deixa "[...] em alerta sempre, continuamente expostos a novas tentações, num estado de excitação incessante - e também, com efeito, em estado de perpétua suspeita e pronta insatisfação.” (BAUMANN, 1999, p. 91)

Sob essa perspectiva imposta pela lógica do mercado, as empresas transnacionais privadas, em especial, as alimentares, cosméticas e farmacêuticas buscam na natureza "novos produtos" para abastecer esses consumidores ávidos por produtos "inovadores", no intuito de atender/satisfazer suas necessidades. É possível verificar que a "[...] sociedade de consumo incita-nos a viver num estado de perpétua carência, levando-nos a ansiar continuamente por algo que nem sempre podemos comprar." (LIPOVETSKY, 2007, p. 23)

A mudança impostas pela lógica econômica globalizada deflagra imbricações na seara ecológica, pois o novo modelo de sociedade agora passa a ser alicerçado no consumo e necessita de recursos naturais para atender as demandas do mercado, onde "os modos de vida produzidos pela modernidade nos desvencilharam de todos os tipos tradicionais de ordem social, de uma maneira que não têm precedentes.” (GIDDENS, 1991, p. 10). Para captar insumos naturais para a fabricação de "novos produtos" a fim de atender o anseio do mercado/consumidores através da expropriação dos recursos naturais para assegurar o ciclo de consumo.

\footnotetext{
5 Na percepção de Deleuze e Guattari (2010, p. 09-10) a esquizofrenia causada pelo consumismo estaria vinculada ao processo de produção, onde os filósofos asseveram que "não pretendemos estabelecer um pólo naturalista da esquizofrenia. O que o esquizofrênico vive especificamente, genericamente, não é, de maneira nenhuma, um pólo especifico da natureza, mas a natureza como processo de produção. E o que é que aqui significa processo? É provável que, a um certo nível, a natureza se distinga da indústria: por um lado, a indústria opõe-se à natureza, por outro transforma os seus materiais, por outro restitui-lhe os seus detritos, etc. Esta relação homem-natureza, indústrianatureza, sociedade-natureza, condiciona, na própria sociedade, a distinção de esferas relativamente autônomas a que chamamos produção, distribuição, consumo, mas este nível de distinções gerais, considerado na sua estrutura formal desenvolvida, pressupõe (como Marx o demonstrou) não só o capital e a divisão do trabalho, mas também a falsa consciência que o ser capitalista tem necessariamente de si e dos elementos cristalizados de um processo de conjunto. Porque na verdade - espantosa e negra verdade que surge no delírio - não há esferas nem circuitos relativamente independentes: a produção é imediatamente consumo e registro, o consumo e o registro determinam diretamente a produção, mas determinam-na no seio da própria produção . Que tal modo que tudo é produção: produção de produções, de ações e de reações; produç̃̃es de registros, de distribuições e de pontos de referência; produções de consumos, de volúpias, de angústias e dores. Tudo é produção: os registros são imediatamente consumidos, destruídos, e os consumos diretamente reproduzidos. É este o primeiro sentido do processo: inserir o registro e o consumo na própria produção, torná- los produções de um mesmo processo. Em segundo lugar, desaparece também a distinção homem/natureza: a essência humana da natureza e a essência natural do homem identificam-se na natureza como produção ou indústria, isto é, afinal, na vida genérica do homem. A indústria deixa assim de ser entendida numa relação extrínseca de utilidade para o ser na sua identidade fundamental com a natureza como produção do homem e pelo homem."
} 
Para atingir tal intento se faz necessário o auxilio da ciência ${ }^{6}$. Assim, o modelo de ciência moderna reformula a relação entre homem/natureza e suas consequencias são sentidas nas mais diversas áreas do conhecimento, a humanidade atravessa um momento ímpar, de grandes mudanças. Dessa forma, se consolida a hegemonia do projeto de ciência sob auspcio eurocêntrico no mundo, o "desaparecimento do saber local por meio de sua interação com o saber ocidental dominante acontece em muitos planos, por meio de muitos processos [...] fazem o saber local desaparecer simplismente não o vendo, negando a sua existência.” (SHIVA, 2003, p. 22)

Para assegurar a manutenção da lógica do mercado calcada num modelo de sociedade consumista é indispensável garantir, o acesso à matéria prima necessária para a confecção dos bens/produtos, aos consumidores que tenham poder aquisitivo para satisfazer as suas necessidades. A iniciativa privada carece do aporte dos Estados, para realização de políticas públicas que atendam/assegurem aos seus interesses no processo de prospecção dos recursos naturais, bem como do auxilio do sistema jurídico para atuar como mecanismo para a regulação dos conflitos nesta área.

Diante da construção dessa conjectura nefasta se torna possível delinear que o “fenômeno de globalização não está ligado somente à economia possuindo também uma natureza política, tecnológica e cultural em uma influência interna sobre nossas vidas (comportamentos, formas de ver o mundo).” (TYBUSCH, 2011, p. 37). A globalização instaura uma crise ambiental que perpassa o referencial ecológico, haja vista, que a complexidade social ocasionou a distribuição dos riscos, com ênfase, nos riscos ecológicos e a saúde humana, esta modalidade de risco afeta os extratos sociais de forma diferenciada.

\footnotetext{
${ }^{6} \mathrm{O}$ modelo ocidental de fazer ciência ainda impera, na acepção de Shiva (2003, p. 23) "os modelos de ciência moderna que promoveram essas visões derivam menos da familiaridade com uma prática científica real e mais familiaridade com as versões idealizadas que deram a ciência um status epistemológico especial. O positivismo, o verificacionismo e o falsificanismo basearam-se todos no pressuposto de que, ao contrário das crenças tradicionais, das crenças locais do mundo, que são construídas socialmente, pensava-se que o saber científico moderno era determinado sem a mediação social. Os cientistas, de acordo com o método científico abstrato, eram vistos como pessoas que faziam afirmações correspondentes às realidades de um mundo diretamente observável. Os conceitos teóricos de seu discurso eram considerados, em princípio redutíveis a afirmações observacionais diretamente verificáveis. Novas tendências da filosofia e da sociologia questionaram os pressupostos positivistas, mas não questionaram a superioridade dos sistemas ocidentais."
} 
A prática da política econômica neoliberal exclui o indivíduo e traz como uma de suas consequências, mais sinistra, o processo de "coisificação" do ser humano, onde o indivíduo é reduzido a mero espectador da realidade social em que se encontra inserido, incapaz de mudála. Nesse cenário, assegura Martins (2003, p. 32), que o fenômeno da exclusão social é consequência da metamorfose impetrada pela globalização econômica que torna “[...] todos os seres humanos seres descartáveis, reduzidos à condição de coisa, forma extrema da vivência da alienação e coisificação da pessoa.”

A sensação de insegurança desencadeada por esse processo tem afetado o modo de vida dos indivíduos em sociedade, e assevera o processo de estratificação social $^{7}$. A solidificação desse paradigma social ocasiona o aumento da desigualdade social através da vulnerabilidade econômica, assim a globalização tende a "periodizar a vida humana, institucionalizando as transições das pessoas da família para a escola ou o trabalho, instituindo a idade ideal para se casar ou se aposentar, entre outras.” (BASSIT, 2000, p. 222)

Nesse ínterim, ocorre a consolidação, a padronização e a universalidade de inúmeras conjunções institucionais que ocasionam uma maior segregação social ${ }^{8}$. Nessa perspectiva, os indivíduos em situação de vulnerabilidade econômica são os mais propensos a se tornarem “invisíveis”, ou seja, não são mais reconhecidos pelos outros indivíduos, pela sociedade ou pelo Estado enquanto sujeitos de direitos quer “[...] seja pela indiferença, seja pelo preconceito, o que nos leva a compreender que tal fenômeno atinge tão somente aqueles que estão à margem da sociedade.” (PORTO, 2009)

O indivíduo em situação de vulnerabilidade econômica passa por um processo discriminação social, uma vez, que destoa dentro do sistema econômico hegemônico, pois não consegue mais consumir da mesma forma que o resto da população. Sob essa lógica de viés economicista se torna possível vislumbrar a postura do ente estatal que diante desse cenário "lava as mãos à vulnerabilidade e à incerteza provenientes da lógica (ou da ilogicidade) do

\footnotetext{
${ }^{7}$ O conceito de estratificação social esta baseada no pensamento de Pedro Demo $(1985$, p. 92$)$, o qual afirma que "estratificação social significa o modo como cada sociedade institucionaliza as desigualdades sociais, ou seja, como as distribui. Dizemos que isto é um conflito estrutural, porque admitimos, como hipóteses de trabalho, que cada fase histórica o reveste de cor própria, mas não há história sem ele, e mais, a historicidade, que faz da sociedade um fenômeno intrinsecamente processual, se origina e se alimenta deste conflito."

${ }^{8}$ Sob a percepção desse fenômeno de Boaventura de Sousa Santos (2001, p. 258) apregoa que "tais excessos atingem, não só o modo como se trabalha e produz, mas também o modo como se descansa e vive; a pobreza e as assimetrias das relações sociais são a outra face da alienação e do desequilíbrio interior dos indivíduos; e, finalmente, essas formas de opressão não atingem especificamente uma classe social e sim grupos sociais transclassistas ou mesmo a sociedade no seu todo."
} 
mercado livre, agora redefinida como assunto privado, questão que os indivíduos devem tratar e enfrentar com os recursos de suas posses particulares." (BAUMAN, 2005, p .67)

Entre os fatores que deflagram o processo de invisibilidade social destacam-se os fatores de ordem social, cultural, econômico e estético. A invisibilidade social pode desencadear processos depressivos relacionados com o abandono e da própria aceitação da condição de "ninguém", de outra banda, tal fenômeno pode ocasionar um processo de mobilização organizacional dessa minoria no sentido buscar novamente visibilidade social. (GACHET, 2014)

Sob o prisma da invisibilidade social ocasionada pela situação de vulnerabilidade econômica o individuo acaba por ser arrastado por esse turbilhão de mudanças decorrentes da estrutura social, e passa a ser refém dessa nova ordem social. Esse fenômeno social acaba por demonstrar que a sociedade moderna tem menosprezo por esses indivíduos, determinando assim a sua consequente exclusão, já que estes não consomem segundo a lógica do capital, se tornam um fardo para esse modelo social. A supremacia dessa conjectura se delineia no padrão adotado na sociedade contemporânea, onde todos os indivíduos devem produzir/consumir.

O indivíduo passa a desconhecer o seu papel dentro deste novo contexto social, eis que a globalização cria uma sociedade preocupada apenas com as relações de consumo entre os indivíduos. Sob esse prisma, se afigura uma nova forma de exclusão social, onde o individuo em situação de vulnerabilidade econômica, onde "tudo o que é sólido desmancha no ar, tudo o que é sagrado é profanado, e os homens são finalmente forçados a enfrentar com sentidos mais sóbrios suas reais condições de vida e sua relação com outros homens." (BERMAN, 1982, p. 87)

Nesse sentido, a questão evolvendo desenvolvimento/sustentabilidade passa a ser direcionada para áreas que não interfiram no modelo econômico posto, ou seja, no modelo capitalista. Assim, a busca pela implantação de um modelo de desenvolvimento econômico alternativo, com vistas a resguardar o equilíbrio socioambiental, em especial, na acesso/proteção/tutela dos recursos naturais de forma equitativa para as gerações presentes e futuras esbarra em inúmeras dificuldades de implantação, haja vista, que este preceito vai contra a lógica do mercado. 


\section{O princípio intergeracional como mecanismo de materialização do acesso equitativo universalizado aos recursos naturais}

O princípio intergeracional possui a premissa de tentar articular um direito voltado para a tutela/garantia/necessidade de pessoas indeterminadas, haja vista, que os indivíduos que pretende tutelar ainda não "existem". Portanto, seu objeto de tutela/garantia/necessidade está condicionando a um futuro incerto. Diante do paradigma jurídico exegético, o direito tradicional não propicia uma tutela jurídica adequada à referida problemática, principalmente no resguardo do acesso equitativo as recursos naturais, pois não tem condições de assegurar o direito a um meio ambiente saudável e equilibrado para as gerações presentes e futuras.

A Conferência de Estocolmo, em 1972, será precursora ao prolatar inúmeros princípios atinentes ao Meio Ambiente Humano, e constitui-se num marco ecológico, uma vez, que os princípios ambientais ventilados nos seus documentos contaminarão diversas Cartas Constitucionais pelo mundo, com foco, na preservação do acesso equitativo os recursos naturais para as gerações presentes e futuras. Sob essa perspectiva, elevará esses preceitos ambientais ao patamar de direito humanos e/ou fundamental para os povos e o modelo de desenvolvimento econômico em nível global.

A alteração desse paradigma se torna essencial, diante da construção de um cenário ecológico catastrófico provocado pelo processo de industrialização global, essa conduta tem ocasionado o exaurimento dos recursos naturais provocado pelo seu uso indiscriminado para manter abastecido o processo de fabricação de "novos" bens/produtos com o objetivo de atender as necessidades de demanda do mercado consumidor. Para refrear esse processo "seria necessário um marco intergeracional de cooperação, que objetiva a longo prazo o uso dos recursos naturais de acordo com uma ética sobre o crescimento econômico limitado e orgânico." (PÉREZ LUÑO, 2012, p. 47)

O preceito da equidade intergeracional está consagrado na Conferência de Estocolmo, mais precisamente no item segundo do referido dispositivo, ao preceituar que cabe aos povos do mundo e a todos os governos proteger e melhorar o meio ambiente como uma questão fundamental para o bem estar dos povos e para o desenvolvimento econômico global. Nessa conjectura, tal preposição passa a ser dever do Estado e da sociedade primar pela construção de mecanismos eficazes para materializar o acesso equitativo a um meio ambiente sadio e equilibrado para as gerações presentes e futuras. 
Apesar do preceito da equidade intergeracional estar entranhando em nossa Carta Magna, o Estado não efetiva políticas socioambientais para materializá-lo. A degradação ambiental, em especial, a proveniente da desigualdade econômica não pode ser suplantada por completo. A práxis de políticas públicas ambientais eficazes auxiliaria no abrandamento da problemática ecológica, bem como propiciaria a construção de mecanismos que auxiliassem no controle do acesso equitativo dos recursos naturais para as gerações presentes e futuras, porém é visto que "o Estado intervém nas relações sociais não para mudá-las na essência, mas para domesticar o conflito de classes que abrigam, mantendo-o, dentro do possível, latente e controlado." (CORRÊA 2002, p. 177)

O ordenamento jurídico tradicional por si só não pode impor uma conduta humana consciente com relação à preservação ecológica. Diante da atual conjectura a mudança deve ser desencadeada pela alteração do comportamento ético dos indivíduos. $\mathrm{Na}$ filosofia aristotélica, os conhecimentos práticos eram o que determinavam a conduta de como o homem deveria produzir e agir no mundo, por isso, o conhecimento prático estava ligado à ação dos indivíduos. Sob a ótica aristotélica a ética e a política se configuram em conhecimentos práticos, quando estes são utilizados pelos indivíduos virtuosos produzem o bem comum. A racionalidade, na concepção aristotélica, impele o ser humano a pensar/julgar a sua conduta determinando o se modo de agir na busca do bom, do justo e do nobre. (ARISTÓTELES, 2001)

A racionalidade humana tem a função de desvelar a verdade implícita do mundo. Dessa forma, o conhecimento propicia o processo de aprendizagem pelo pensamento, a fim, de que o ser humano aprenda acerca dos fenômenos e a forma como esses fenômenos operam. $\mathrm{Na}$ acepção aristotélica o agir humano está condicionado a essa realidade, pois a espécie humana é dotada de racionalidade. Contudo, essa racionalidade pode não ser o suficiente para nortear as ações dos seres humanos em torno da geração do bem comum para os indivíduos. Assim, Aristóteles afiança que o conhecimento acerca das verdades morais acaba por não ser o suficiente para orientar as ações humanas, pois a conduta do agir por meio de ações moralmente boas. (ARISTÓTELES, 2001)

Já, a ética Kantiana ventila a necessidade de o próprio indivíduo ser a medida e a fonte do dever, onde o indivíduo deve pautar as suas ações por meio da criação de valores morais próprios. Sob essa concepção o homem é capaz de se auto-regular e dessa maneira se autodetermina em liberdade, uma vez, que a razão humana é caracterizada por autonomia e liberdade para determinar a sua respectiva lei norteada pela universalidade. Para Kant, o 
conhecimento possui sua gênese na experiência, entretanto, tal fato por si só não prova que o conhecimento na sua totalidade derive da experiência. (KANT, 2006)

A concepção kantiana sobre o preceito da liberdade está vinculada a noção do ser humano em conduzir as suas ações norteadas por um conjunto de regras atribuídas pela própria razão, onde o indivíduo obedece à lei moral sem deixar de ser livre. Pois, frente essa premissa o seu agir está condicionado há uma lei imposta pela própria moral, nesse princípio está fundamentada a autonomia da vontade kantiana, haja vista, que a liberdade consiste em condição essencial para a moral. (KANT, 2006)

Deste modo, obedecer às leis morais não remove à dignidade do ser humano, uma vez, que essa conduta é autônoma e intrínseca a dignidade do homem por meio da racionalidade. Frente essas construção teórica, Kant propagará a possibilidade de uma vontade universalisante, por meio dos imperativos categóricos, pois esses coordenam as inúmeras vontades individuais no universo jurídico, esse intricado se dá sob o auspicio das leis universais de liberdade, uma vez, que todos os indivíduos participam do processo de construção das leis as quais posteriormente se submetem.

Diante da conjectura ética estabelecida por Kant, o filósofo Hans Jonas formulará o princípio da responsabilidade com o intuito de realizar um diálogo crítico permeado pela ética frente às novas tecnologias advinda da sociedade industrial. Para tanto, Jonas conjectura um novo imperativo categórico vinculado à ação humana, ou seja, delineia um novo padrão ético para o agir humano, onde a ação dos indivíduos a partir da racionalidade deve determinar uma nova forma no agir coletivo, frente essa nova postura seria possível tutelar um bem público a partir da premissa da coletividade em detrimento da individualidade. (JONAS, 2006)

Deste modo, Jonas assevera a necessidade de "levar em consideração a condição global da vida humana, o futuro distante e até mesmo a existência da espécie.” (JONAS, 2014, p. 40). Sob essa perspectiva, o filósofo determina a influencia do desenvolvimento tecnológico na construção de uma teoria ética comprometida com uma responsabilidade coletiva de forma a produzir um agir ético coletivo livre, com ênfase, na conduta das gerações presentes e futuras no tocante ao acesso equitativo aos recursos naturais.

Para o filósofo a incerteza transtemporal sobre a sobrevivência da espécie humana se configura num equívoco tendo em vista que não se pode separar o ser humano da natureza. Nessa perspectiva o filósofo propõe a necessidade de serem repensados os conceitos fundamentais da ética sob a ótica do princípio da responsabilidade, haja vista, que o homem 
deve "procurar não só o bem humano, mas também o bem de coisas - extra-humanas, ou seja, alargar o conhecimento dos fins em si mesmo para além da esfera do homem." (JONAS, 2014, p. 40)

$\mathrm{Na}$ percepção do filósofo Hans Jonas o princípio da responsabilidade seria um alargamento da ética vinculado à racionalidade a partir da construção de um novo imperativo categórico, com a premissa para determinar um agir coletivo livre com responsabilidade diante das práticas do ser humano. Sob essa nova conjectura da ética vinculada a um agir coletivo o filósofo determina "a natureza como uma responsabilidade humana é seguramente um novum sobre o qual uma nova teoria ética deve ser pensada.” (JONAS, 2006, p. 39)

O princípio da responsabilidade impõe um dever ético no agir coletivo com as gerações futuras, uma vez, que o desenvolvimento tecnológico cria uma sociedade global de risco, onde o risco passa a ser um risco transtemporal condicionado há um futuro incerto, assim, os danos não podem ser revertidos depois de desvelados. Diante disso, é preciso que haja comprometimento das gerações presentes com as gerações futuras, por isso deve haver um agir coletivo ético no presente, no sentido de assegurar que os recursos naturais atendam as suas necessidades das gerações presentes sem prejudicar as gerações futuras.

Frente essa conduta, surge à problemática da equidade entre as gerações, pois à medida que a geração presente faz uso dos recursos naturais do planeta no intuito de produzir riqueza, este agir deve primar, dentro de um agir ético coletivo, no sentido de repartir esses mesmos recursos naturais que produzem riqueza com as gerações futura. De outra banda, já é possível constatar algumas mudanças nessa conjectura, pois "o apreço pela natureza nunca foi tão grande como actualmente, em especial nos países que resolveram os problemas da pobreza e da fome e onde restam relativamente poucas terras virgens." (SINGER, 2004, p. 182)

Sob essa premissa, o desenvolvimento/uso de recursos naturais e culturais na produção de riqueza provoca problemas na efetivação do preceito da equidade intergeracional. Pois, ocorre o processo de esgotamento dos recursos naturais para as gerações futuras, nesse mesmo sentido se torna possível verificar a deterioração da qualidade desses recursos devido ao seu uso indiscriminado, e assim acontece um impacto pernicioso ocasionado pela utilização indevida dos recursos naturais pelas gerações passadas. (WEISS, 2004, p. 41)

Deste modo, a Teoria da Equidade Intergeracional delineada pela jurista americana Edith Brown Weiss determina o compromisso entre as gerações humanas no que se refere ao direito ao acesso ao meio ambiente sadio e equilibrado, onde cabe à geração presente resguardar o 
meio ambiente com as características que recebeu para assim repassá-lo as futuras gerações para que esta possa usufruir dos mesmos benefícios advindos do acesso aos mesmos recursos naturais, "esto nos impone las obligaciones de cuidar al planeta a la vez que nos otorga ciertos derechos para usarlo." (WEISS, 2004, p. 52)

No âmbito da filosofia de diversas culturas figura o preceito da equidade intergeracional, nessa acepção o ser humano é apontado como o responsável por administrar racionalmente o meio ambiente no qual se encontra inserido. Sob essa premissa, a tese fundamental gira em torno da obrigação do ser humano em conservar de forma equitativa os benefícios advindos dos recursos naturais do planeta para as gerações presentes e futuras, frente essa concepção "encuentra profundamente enraizada em la variada tradición jurídica de la comunidad internacional." (WEISS, 2004, p. 52)

Diante disso, Weiss (2004) fundamenta a Teoria da Equidade Intergeracional sob as seguintes premissas: a) conservação das opções: onde cada geração presente necessita preservar a biodiversidade para as gerações futuras. Para tanto, deve devolver essa biodiversidade em qualidade análoga as recebidas das gerações anteriores; b) conservação da qualidade: é responsabilidade de cada geração conservar a biodiversidade para que a próxima geração possa usufruir da mesma qualidade dos recursos naturais que as gerações anteriores; c) conservação do acesso: onde cabe a cada geração preservar o legado passado e criar mecanismos equitativos de acesso à biodiversidade para as gerações futuras.

A Declaração sobre as Responsabilidades das Gerações Presentes em Relação às Gerações Futuras, de 1997, corrobora com a necessidade de resguardar o uso dos recursos naturais para as gerações presentes e futuras. Frente essa conjectura, é promulgado em seu artigo primeiro a necessidade e os interesses das gerações futuras pontuando que "as gerações presentes têm a responsabilidade de garantir que as necessidades e os interesses das gerações presentes e futuras sejam plenamente salvaguardados." (UNESCO, 1997)

Nesse sentido, a justiça entre as gerações presente e futura arquitetada pela teoria da equidade intergeracional deve levar em conta a materialização de certos preceitos humano e/ou fundamentais que sirvam como base para os direitos e as obrigações intergeracionais, para dessa forma, reconhecer a equidade intregeracional enquanto um princípio normativo regulador do acesso aos recursos naturais. Frente essa constatação, "el derecho internacional tiene larga tradición em el empleo de principios de equidad para interprtar documentos y alcanzar decisiones a fin de lograr um resultado justo.” (WEISS, 2004, p. 66) 
O princípio da equidade intergeracional determina um rol de obrigações globais na tutela dos recursos naturais, e requer que cada geração realize a conservação dos recursos naturais de forma equitativa. Diante dessa constatação Weiss (2004, p.77) estipula que as obrigações intergeracionais assumem caráter jurídico à medida que são especificadas e incorporadas por meio de acordos internacionais. Para posteriormente se irradiarem na forma de princípios gerais do direito junto às cartas constitucionais dos países e em suas legislações infraconstitucionais.

Assim, os preceitos intergeracionais poderão nortear a resolução de problemas atinentes à conservação da biodiversidade e no combate a poluição dos recursos naturais. Nesse sentido, a equidade intergeracional impõe obrigações para o uso/acesso dos recursos naturais no âmbito local/global, com o objetivo de assegurar a conservação do acesso equitativo a estes recursos naturais, uma vez, que a degradação ecológica se constitui num "problema de ordem prática que transcendem as preocupações nacionais. São problemas transnacionais, pois não se pode mensurá-los somente em escala local.” (ARAUJO; TYBUSCH, 2009, p. 80).

Para tanto, as ações envolvendo a materialização da equidade intergeracional só tem significado quando esse preceito e afiançado tanto pelo direito internacional e como pelo direito interno. Diante da construção desse cenário, essas obrigações/deveres intergeracionais envolvendo o acesso equitativo aos recursos naturais podem ser visualizados diante de um "sistema jurídico internacional dinámico, en el cual los estados, las organizaciones no gubernamentales, las corporaciones y los indivíduos tienen importantes roles de implementación.” (WEISS, 2004, p. 79)

De tal modo, Weiss (2004) elenca cinco categorias para os deveres de uso dos recursos naturais para as gerações presentes e futuras: 1) a necessidade de materializar ações para conservar os recursos naturais para as gerações presentes e futuras; 2) a obrigação de criar mecanismos de acesso equitativos para o uso dos recursos naturais; 3) a necessitar de minimizar o impacto sobre a utilização dos recursos naturais no intuito de garantir a sua qualidade; 4) atuar para evitar desastres e prestar assistência em caso de emergência; e 5) o dever de suportar os custos causados por danos os recursos naturais e a qualidade ambiental.

Essas categorias ventiladas pela jurista visam assegurar uma estrutura mínima que prime pela conservação/acesso equitativo dos recursos naturais. Para atingir tal intento, as mesmas necessitam ser absorvidas/incorporadas pelo direito internacional no sentido de criar mecanismos jurídicos que visem à proteção/tutela do acesso equitativo dos recursos naturais na esfera internacional, para assim provocar uma reverberação junto os mecanismos jurídicos internos, uma vez, que os problemas ecológicos contemporâneos são de ordem complexa e 
tem por característica, não raras vezes, ser transnacionais, ou seja, afetam mais de um Estado influenciando o modo de vida dos indivíduos em escala global.

Portanto, se faz necessário primar pelo uso racional dos recursos naturais, essa obrigação tem sua base no direito comum das gerações presentes e futuras ao acesso/utilização equitativa dos recursos naturais para a obtenção de riquezas e a manutenção da subsistência da espécie. Nesse panorama se pode conjecturar que a equidade intergeracional está intimamente ligada ao modelo de desenvolvimento econômico hegemônico, frete essa constatação Moscovici (2007, p. 38) pontua que "de fato, qualquer que seja a posição social de um indivíduo ou de um grupo, ele se encontra no centro de uma sociedade, ele se aproveita da economia mundial. Se ele está na periferia, de uma maneira ou outra ele sofre."

Pode-se afirmar que modelo de crescimento econômico contemporâneo acaba segregar os indivíduos segundo o seu poder aquisitivo, a lógica do sistema econômico impõe um conjunto de axiomas aos recursos naturais pela lógica do capital, e dessa forma acaba por privatizá-los na forma de delimitação do seu acesso. Frente essa conjectura, Ferrajoli (2015, p. 226) determina a necessidade de "impor a garantia de todos estes bens vitais, sejam artificiais ou naturais, como bens de todos contra a concepção mercadológica ou contra as devastações provocadas por um capitalismo desregulado e predatório."

Sob o auspicio dessa lógica perversa imposta pelo modelo econômico hegemônico, é possível vislumbrar o aumento da desigualdade social incitada pelo viés econômico, onde uma pequena parte dos indivíduos acaba se beneficiando frente o modelo de crescimento econômico, cabendo aos demais indivíduos combaterem o status quo visando diminuir o abismo social provocado pela economia, pois "o crescimento contínuo e acelerado só é possível porque há desigualdade. Essa desigualdade se mantém com o crescimento; se ela é exponencial, os mais ricos tornam-se mais ricos, os pobres ainda mais pobres." (MOSCOVICI, 2007, p. 39)

Para tentar contrapor-se a lógica do mercado no que se refere ao acesso equitativo dos recursos naturais por parte dos indivíduos, surge o preceito da equidade intergeracional que está vinculado a uma concepção holística e não fragmentária de compreender o natural, tal concepção está atrelada a perspectiva de que a desigualdade social atua como mola propulsora no processo de degradação do natural, com reflexos no acesso igualitário aos recursos naturais para as gerações presentes e futuras. Sob essa conduta Moscovici (2007, p. 39) conjectura que “o equilíbrio - o estado estacionário - não existe é um tipo ideal de figura teórica. A realidade 
dos seres, da vida se materializa em uma pilha de desequilíbrios, uma sucessão de estados transitórios sem começo nem fim.”

Diante desse cenário, é indispensável (re)pensar mecanismos políticos/jurídicos que viabilizem a materialização do preceito da equidade intergeracional com o intuito de resguardar o acesso equitativo aos recursos naturais para as gerações presentes e futuras que privilegie o tratamento isonômico entre os indivíduos, em detrimento da lógica do econômica neoliberal marcada pelo consumo. Frente essa nova percepção de compreensão do natural Moscovici (2007, p. 39) afirma que existe "uma ecologia estática de equilíbrio, nós devemos transformá-la em uma ecologia dinâmica, em movimento, em que fases de desordem se misturam a fases de ordem, dentre as quais o crescimento é uma delas."

$\mathrm{O}$ preceito da equidade intergeracional constitui-se num instrumento essencial para nortear tanto o debate político internacional/local sobre os limites dos atores sociais no que tange o uso/acesso equitativo dos recursos naturais, bem como para a construção de normas/regramentos jurídicos na esfera internacional e o balizamento da absorção destes pelas Constituições dos países e suas respectivas legislações esparsas com vistas, a concretizar mecanismos jurídicos que concretizem os princípios inerentes a equidade intergeracional para dessa forma garantir a tutela/proteção do acesso equitativo dos recursos naturais para as gerações presentes e as gerações futuras.

\section{CONSIDERAÇÕES FINAIS}

$\mathrm{O}$ artigo teve a premissa de realizar um diagnóstico sobre o processo de mercantilização/depredação dos recursos naturais sob a égide da globalização por meio de uma análise acerca das relações entre indivíduos e o consumo e a conseqüente atuação do princípio da equidade intergeracional como marco regulador através da contaminação da legislação internacional/interna, em especial, das normas que realizam a regulação do acesso equitativo aos recursos naturais para as gerações presentes e futuras.

Nesse ínterim, a globalização ocasiona uma metamorfose em nível global com intensidade desigual devido à posição hegemônica dos países dentro sistema mundial, tal postura gera conflito na construção de políticas econômicas das nações. Os Estados não conseguem fazer frente à nova ordem econômica mundial. A globalização será responsável pelo 
aumento do processo de mercantilização/depredação do natural, uma vez, que a lógica do capital instaura uma sociedade baseada no consumo. Dentro dessa realidade verifica-se que o individuo passa a ser destituído do seu papel de cidadão, uma vez, que ocorre uma redução/efetivação de suas garantias e direitos humanos e/ou fundamentais e da instigação para o consumo atendendo assim a lógica econômica do mercado. Nesse cenário começa a se asseverar a problemática da desigualdade social, uma vez, que a lógica do capital determina que o indivíduo só exista na medida em que consome.

O modelo de desenvolvimento econômico atrelado ao capitalismo, ou seja, está comprometido com a manutenção de uma sociedade de consumo, onde são necessários recursos naturais para a fabricação de insumos/produtos para atender aos desejos dos consumidores. Assim, o crescimento deflagrado pelo desenvolvimento econômico e humano exerce um impacto sobre o ecológico por meio da degradação do natural, haja vista, que existe uma necessidade de analisar a capacidade do natural em suportar as consequiências das aglomerações de pessoas e da utilização dos recursos naturais.

Nessa linha de idéia, o ordenamento jurídico tradicional por si só não pode impor uma conduta humana consciente com relação à preservação ecológica. Diante da atual conjectura a mudança deve ser desencadeada pela alteração do comportamento ético dos indivíduos. O princípio da responsabilidade impõe um dever ético no agir coletivo das gerações presentes para com as gerações futuras, uma vez, que o desenvolvimento tecnológico cria uma sociedade global de risco, onde o risco passa a ser um risco transtemporal condicionado há um futuro incerto, assim, os danos não podem ser revertidos depois de desvelados.

Por derradeiro, se faz necessário a concretização do princípio da equidade intergeracional, uma vez, que o mesmo determina um rol de obrigações globais na tutela dos recursos naturais, e requer que cada geração realize a conservação dos recursos naturais de forma equitativa. Sob essa conjectura a equidade intergeracional está vinculada a uma concepção holística e não fragmentária da natureza, que atrela à desigualdade social como mola propulsora no processo de degradação do natural, com reflexos no acesso igualitário aos recursos naturais para as gerações presentes e futuras. Para tanto, é necessária a construção de mecanismos jurídicos eficazes para materializar o princípio da equidade intergeracional com vistas a assegurar uma qualidade de vida e a proteção ambiental. 


\section{Referências}

ARITÓTELES. Ética a Nicômaco. São Paulo: Martin Claret, 2001.

BASSIT, Ana Zahira. O curso de vida como perspectiva de análise do envelhecimento na pósmodernidade. In: DEBERT, Guita Grin; GOLDSTEIN, D. Políticas do corpo e o curso da vida. São Paulo: Mandarim, 2000, p. 217-234.

BAUMAN, Zygmunt. Vidas desperdiçadas . Rio de Janeiro: Jorge Zahar Ed., 1999.

BAUMAN, Zygmunt. Globalização: As consequencias humanas. Rio de Janeiro: Jorge Zahar Ed., 1999.

. Modernidade e Ambivalência: A privatização da ambivalência. Rio de Janeiro:

Editor Jorge Zahar, 1999.

BECK, Ulrich. Sociedade de risco: Rumo a uma outra modernidade. 2.ed. São Paulo: Editora 34, 2011.

BEDIN, Gilmar Antônio Bedin. Os direitos do homem e o neoliberalismo. 3.ed. Ijuí: Editora Unijuí, 2002.

BERMAN, Marshall. Tudo que é sólido se desmancha no ar - A aventura da Modernidade. São Paulo: Companhia das Letras, 1982.

CANCLINI, Néstor García. Consumidores e cidadãos: conflitos multiculturais da globalização. Rio de Janeiro: Editora UFRJ, 2006.

CASTELLS, Manoel. A era da informação: Economia, sociedade e cultura. V.1: A sociedade em rede. São Paulo: Paz e Terra, 1999.

CORRÊA, Darcísio. A construção da cidadania: reflexões histórico-políticas. 3.ed. Ijuí: Editora Unijuí, 2002.

DELEUZE, Gilles; GUATTARI, Felix. O Anti-Édipo - Capitalismo e esquizofrenia. Tradução de Luís B. L. Orlandi. São Paulo: Editora 34, 2010.

DEMO, Pedro. Sociologia: uma introdução crítica. 2.ed. São Paulo: Atlas, 1985.

FERRAJOLI, Luigi. A democracia através dos direitos: o constitucionalismo garantista como modelo teórico e como projeto político. São Paulo: Revista dos Tribunais, 2015.

GIDDENS, Anthony. O mundo em descontrole. Tradução de Maria Luiza X. de A. Borges. Rio de Janeiro: Record, 2007.

Sociologia. Tradução de Sandra Regina Netz. 4.ed. Porto Alegre: Artemed, 2005.

As consequências da modernidade. Tradução de Raul Fiker. São Paulo: Editora UNESP, 1991. 
JONAS, Hans. Técnica, medicina e ética. São Paulo: Paulus Editora, 2014

O princípio da responsabilidade. Ensaio de uma ética para uma civilização tecnológica. Rio de Janeiro: PUC Rio, 2006.

KANT, Immanuel. Fundamentação da Metafísica dos Costumes e Outros Escritos. São Paulo: Martin Claret, 2006.

LIPOVETSKY, Gilles. A sociedade da decepção. Barueri: Manole, 2007.

MARTINS, José de Souza. A sociedade vista do abismo: novos estudos sobre exclusão, pobreza e classes sociais. 2.ed. Rio de Janeiro: Vozes, 2003.

MOSCOVICI, Serge. Natureza - Para pensar a ecologia. Rio de Janeiro: Mauad X, 2007. PÉREZ LUÑO, Antonio Enrique. Perspectivas e tendências atuais do Estado

Constitucional. Porto Alegre: Livraria do Advogado, 2012.

PORTO, Juliana. Invisibilidade social e a cultura do consumo. Disponível em:

$<$ http://www.dad.pucrio.

br/dad07/arquivos_downloads/43.pdf>. Acesso em: 06 set. 2014.

SANTOS, Boaventura de Sousa. Os processos da globalização. In.: globalização e as ciências sociais. São Paulo: Cortez Editora, 2011. . (Org.). A

Pela mão de Alice: O social e o político na pós-modernidade. 8.ed. São Paulo: Cortez, 2001.

SINGER, Peter. Libertação Animal. Porto Alegre: Lugano Editora, 2004.

SHIVA, Vandana. Monoculturas da mente: perspectivas da biodiversidade e da biotecnologia. São Paulo: Gaia, 2003.

TYBUSCH, Jerônimo Siqueira; ARAÚJO, Luiz Ernani Bonesso de. Biodiversidade na América Latina: ecologia política e a regulação jurídico-ambiental. In: Clóvis Eduardo Malinverni da Silveira (Org.). Princípios do direito ambiental: articulações teóricas e aplicações práticas. Caxias do Sul: EDUCS, 2013.

TYBUSCH, Jerônimo Siqueira. Sustentabilidade multidimensional: elementos reflexivos na produção da técnica jurídico-ambiental. 2011. 222 p. Tese (doutorado) - Universidade Federal de Santa Catarina, Centro de Filosofia e Ciências Humanas. Programa de PósGraduação Interdisciplinar em Ciências Humanas.

TOSTES, Ana Paula B.. Identidades transnacionais e o estado: viço e teimosia?. Lua Nova [online]. 2004, n.63, pp.39-66. ISSN 1807-0175. Disponível em < http://dx.doi.org/10.1590/S0102-64452004000300003. . . Acesso em: 11 Mar. 2016.

UNESCO. Declaração sobre as Responsabilidades das Gerações Presentes em Relação às Gerações Futuras. Disponível em 
$<$ http://unesdoc.unesco.org/images/0011/001108/110827por.pdf $>$. Acessado em: 10 Nov. 2015.

WEISS, Edith Brown. Um mundo justo para las futuras generaciones: Derecho internacional, Partimonio común y Equidad intergeracional. Santiago: Universidad de Chile, 2004. 